Lingua e Literatura, $\mathrm{n}^{\circ}$ 24, p. 9-10, 1998.

\title{
NOTA EXPLICATIVA
}

Flávio Wolf de Aguiar

Nos dias 12, 13 e 14 de Agosto de 1998 cerca de quarenta intelectuais, professores e autoridades universitárias reuniram-se, com um público numeroso e interessadíssimo, para apresentarem trabalhos e consideraçōes em homenagem ao professor Antonio Candido. A abertura, no dia 12, deu-se no Centro Universitário Maria Antônia, sede da antiga Faculdade de Filosofia, Ciências e Letras. As demais sessões, nos dias subseqüentes, deram-se no Anfiteatro da História, na Cidade Universitária, com transmissão simultânea por televisāo, para a Anfiteatro de Geografia, tal era o acúmulo de público. O evento, que se chamou Antonio Candido - pensamento e militância, foi organizado pela Faculdade de Filosofia, Letras e Ciências Humanas, Instituto de Estudos Avançados e Núcleo de Literatura e Critica (com sede na casa Mário de Andrade) da Universidade de Sāo Paulo, pelo Instituto de Estudos da Linguagem da Universidade Estadual de Campinas, pela Faculdade de Ciências e Letras de Assis, da Universidade Estadual Paulista, pela Associaçāo dos Docentes da Universidade de São Paulo, ADUSP-Seção Sindical, e pela Fundação Perseu Abramo. Houve também uma exposição Diálogos com Antonio Candido - organizada pelo pessoal do Núcleo de Literatura e Crítica e do Centro de Documentaçāo Alexandre Eulálio da Unicamp, com apoio do Museu Paulista e da Biblioteca da FFLCH, paralelamente ao evento. Os trabalhos apresentados, exceto alguns poucos, nāo versavam

(*)Professor de Literatura Brasileira do Departamento de Letras Clássicas e Vernáculas, FFLCHUSP. Coordenador do Centro Ángel Rama da FFLCH. Presidente da Comissão Organizadora de Antonio Candido - pensamento e militância. 
10 AGUIAR, Flávio Wolf de. Nota explicativa. Lingua e Literatura, $\mathrm{n}^{\circ} 24$. p. 9-10, 1999.

diretamente sobre a obra ou as atividades do homenageado, mas sim eram direta ou indiretamente inspirados por ela ou ele. Como forma de registro do evento, e também como homenagem ao professor, Lingua $e$ Literatura apresenta aqui o trabalho do professor Benedito Nunes, lido na ocasião. 